\title{
Highly Selective Liquid Membrane Sensor Based on 1,3,5-Triphenylpyrylium Perchlorate for Quick Monitoring of Sulfate Ions
}

\author{
Mohammad Reza Ganjali," Maryam Ghorbani, Azadeh Daftari, Parviz Norouzi, \\ Hooshang Pirelahi, and Hossein Daryanavard Dargahani \\ Deparment of Chemistry, Tehran Chiversitv. P.O. Box 14155-6455, Tehran. Iran \\ Received Mav 2, 2003
}

\begin{abstract}
A highly selective membrane electrode based onl.3.5-triphenylpyrylium perchlorate (TPPP) is presented. The proposed electrode shows very good selectivity for sulfate ions over a wide variety of common inorganic and organic anions. The sensor displays a nice Nernstian slope of $-29.7 \mathrm{mV}$ per decade. The working concentration ranges of the electrode is $1.0 \times 10^{-1}-6.3 \times 10^{-6} \mathrm{M}$ with a detection limit of $4.0 \times 10^{-6} \mathrm{M}(480 \mathrm{ng}$ per $\mathrm{mL})$. The response time of the sensor in whole concentration ranges is ven short $(<6 \mathrm{~s})$. The response of the sensor is independent on the $\mathrm{pH}$ range of 2.5-9.5. The best performance was obtained with a membrane composition of $32 \%$ PVC. $59 \%$ benzyl acetate. $5 \%$ TPPP and $4 \%$ hexadecyltrimethy lammonium bromide. It was successfully used as an indicator electrode for titration of sulfate ions with barium ions. The electrode was also applied for determination of salbutamol sulfate and paramomỵcine sulfate
\end{abstract}

Key Words : Py̆ylium derivative. TPPP. Sulfate, Potentionetry, PVC

\section{Introduction}

Investigations about ion selective electrodes are steadily increasing. The rapid development of these electrodes. reflect the extent to which these devices meet the need for accurate. cheap and rapid analytical and control techniques. These electrodes are being used in clinical analysis and in routine control analysis of cations and anions. ${ }^{1}$ It has been well documented that the selective complexation of anions by synthetic ionophores can be used to design anion selective electrodes that exhibit non-Hofmeister selectivity pattern, i.e., selectivities that are not based solely on the analy te lipophilicity. ${ }^{2}$ Most of these electrodes are based on vitamin $\mathrm{B}_{12}$ derivatives, ${ }^{3.4}$ metalloporphyrines, organomercury conpounds. ${ }^{6}$ Schiff's base complexes of metal ions, ${ }^{7}$ trialkyltin derivatives, ${ }^{8}$ phthalocyanines ${ }^{9}$ and metal complexes of organophosphines. "In all these cases. ligation of the primary anion to the central metal ion is responsible for the observed selectivity:

Recently. new sulfate ion selective sensors based on a bisthiourea ionophore, ${ }^{11}$ a derivative of inidazole, ${ }^{2}$ a zwitterionic bis (guanidinum) ion carrier ${ }^{13}$ a tris (2-aminoethylamine) derivative $^{l+}$ and hydrotalcites ${ }^{15}$ with a Nernstian behavior and relatively wide working concentration range have been reported. The interference effect of anions such as $\mathrm{Cl}^{-}$. $\mathrm{HSO}_{3}^{-}$: $\mathrm{HCO}_{3}^{-}$. $\mathrm{CH}_{3} \mathrm{COO}^{-}$, and $\mathrm{HPO}_{4}{ }^{2-}$ for these new sensors is significantly reduced. but they suffer serious interference from other anions such as $\mathrm{NO}_{3}^{-}, \mathrm{Br}^{-}, \mathrm{F}^{-}, \mathrm{NO}_{2}^{-}$. $\mathrm{ClO}_{4}^{-}$and $\mathrm{SCN}^{-}$. In this work. we wish to introduce a highly selective membrane electrode for quick determination of sulfate ions in various samples based on TPPP.

Corresponding Author. Fax: +98-21-6495291, e-mail: Ganjali akhayan.ut.ac.ir

\section{Experimental Section}

Reagents. Reagent grade $o$-nitrophenyloctyl ether (NPOE), dibutyl phthalate (DBP). benzyl acetate (BA). tetrahydrofuran (THF). hexadecyltrimetlylammonium bromide (HTAB) and high relative molecular weight PVC were purchased from Merck chemical company and used as received. Reagent grade potassium salts of all anions used (all from Aldrich) were of lighest purity available and used without any further purification except for vacuum drying over $\mathrm{P}_{2} \mathrm{O}_{5}$. All other reagents needed were purchased from Merck and used as received. 1.3,5-triphenylpyrylium perchlorate (TPPP) (Fig. 1) was synthesized and purified as described elsewere. ${ }^{16}$ Triply distilled de-ionized water was used throughout.

Electrode preparation. The general procedure to prepare the PVC membrane was to mix thoroughly. 32 mg of PVC, 5 $\mathrm{mg}$ of TPPP, $4 \mathrm{mg}$ of HTAB and $59 \mathrm{mg}$ of BA. Then the mixture was dissolved in $3 \mathrm{~mL}$ of dry freshly distilled THF. The resulting clear mixture was evaporated slowly until an oily concentrated mixture was obtained. A Pyrex tube $(5 \mathrm{~mm}$ i.d.) was dipped into the mixture for about $5 \mathrm{~s}$, so that a nontransparent membrane of about $0.3 \mathrm{~mm}$ thickness is formed. ${ }^{7-3 !}$ Then. the tube was pulled out from the mixture and kept at room temperature for about $24 \mathrm{~h}$. The tube was then filled with intemal solution $\left(1.0 \times 10^{-3} \mathrm{M} \mathrm{K}_{2} \mathrm{SO}_{4}\right)$. The electrode was funally conditioned for $24 \mathrm{~h}$ by soaking in a solution containing $1.0 \times 10^{-2} \mathrm{M} \mathrm{K}_{2} \mathrm{SO}_{4}$.<smiles>Cl[C-][O+](c1ccccc1)c1cc(-c2ccccc2)cc(-c2ccccc2)c1</smiles>

Figure 1. Structure of TPPP. 
Potential measurements. All emf measurements were carried out with following assembly:

$\mathrm{Ag}-\mathrm{AgCl} \mid$ internal solution $\left(1.0 \times 10^{-3} \mathrm{M} \mathrm{K}_{2} \mathrm{SO}_{4}\right) \quad \mathrm{PVC}$ membrane test solution $|\mathrm{Ag}-\mathrm{AgCl}| \mathrm{KCl}$ (satd.)

A Coming ion analyzer $250 \mathrm{pH} / \mathrm{mV}$ meter was used for the potential measurements at $25 \pm 0.1{ }^{\circ} \mathrm{C}$.

\section{Results and Discussion}

Stability constants of different anion-TPPP complexes. It is well known that the TPPP and other pyrylium derivatives have fluorescence property. ${ }^{21}$ Thus, at first we carried out some spectrofluorimetric measurements in acetonitrile solution in order to obtain quantitative information about the anion-TPPP interactions. The fluorescence intensity $v s$. anion/TPPP mole ratio plot for some anions is shown in (Fig. 2). As it is seen, addition of sulfate ion to a TPPP solution resulted in a distinct quenching of the fluorescence of TPPP, and the formation of a stable $1: 1$ sulfate-TPPP complex in solution. While, the presence of other anions displays a gradual decrease in fluorescence intensity, which does not tend to level off even at mole ratio $>2$, indicating that formation of weak complex between TPPP and other anions. The formation constants $\left(\log K_{f}\right)^{22}$

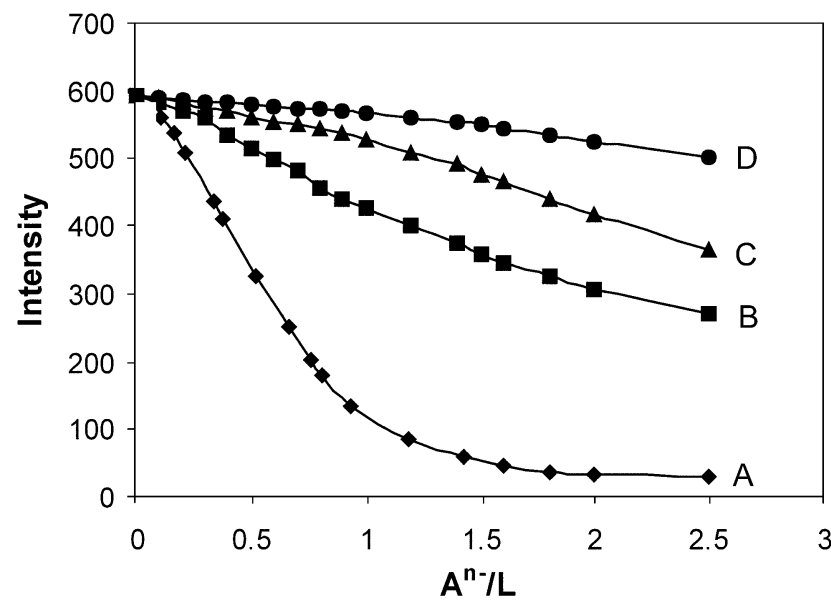

Figure 2. The fluoreseence intensity $v$ s. anion/TPPP mole ratio plot of (A) $\left(\rightarrow \mathrm{SO}_{+}^{2-}\right)$. (B) $\left(\rightarrow-\mathrm{SO}_{3}{ }^{2-}\right)$. (C) $\left(\wedge \mathrm{C}^{-}\right)$. (D) $\left(\rightarrow \mathrm{I}^{-}\right)$.

Table 1. Stability constants of anion-TPPP complexes

\begin{tabular}{|c|c|}
\hline Anions & Log $K_{f}$ \\
\hline $\mathrm{SO}_{4}{ }^{--}$ & $>6.0$ \\
\hline $\mathrm{SO}_{3}{ }^{--}$ & $3.29 \pm 0.05$ \\
\hline $1 \mathrm{PO} \mathrm{H}^{2-}$ & $2.17 \pm 0.03$ \\
\hline $\mathrm{NO}_{2}^{-}$ & $2.91 \pm 0.07$ \\
\hline $\mathrm{NO})_{3}^{-}$ & $2.63 \pm 0.03$ \\
\hline $\mathrm{CH}_{3} \mathrm{COO}^{-}$ & $2.31 \pm 0.05$ \\
\hline $\mathrm{ClO}_{4}^{-}$ & $<2.0$ \\
\hline $1^{-}$ & $2.44 \pm 0.07$ \\
\hline $\mathrm{IBr}^{-}$ & $2.50 \pm 0.03$ \\
\hline $\mathrm{Cl}^{-}$ & $2.39 \pm 0.06$ \\
\hline $\mathrm{F}^{-}$ & $<2.0$ \\
\hline
\end{tabular}

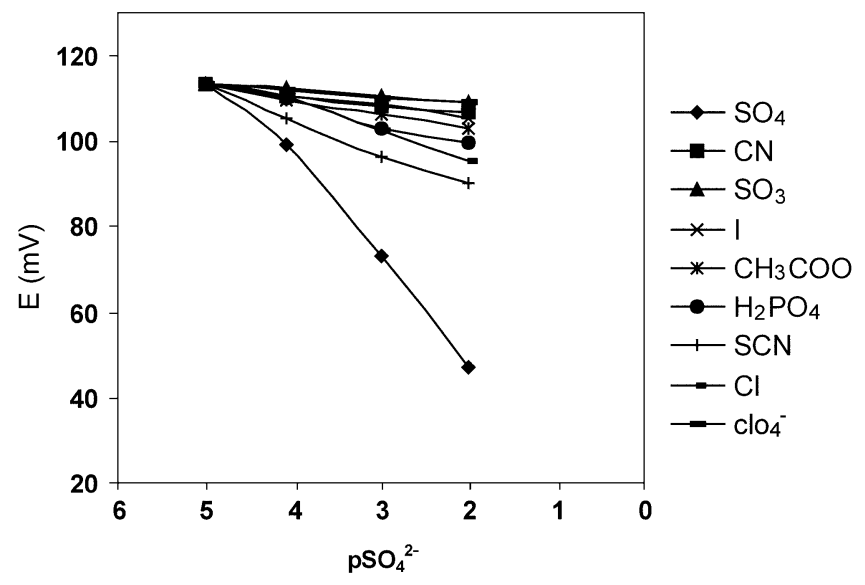

Figure 3. Potential responses ol dillerent ionselective electrodes based on "]PPP (- $\left(-\mathrm{SO}_{1}^{2-}\right) \cdot\left(-\cdot-\mathrm{SCN}^{-}\right) \cdot\left(-\mathrm{Cl}^{-}\right) \cdot\left(-\mathrm{II}_{2} P \mathrm{O}_{1}^{-}\right)$. $\left(* \mathrm{CH}_{3} \mathrm{COO}^{-}\right) \cdot\left(* \mathrm{I}^{-}\right) \cdot\left(-\mathrm{E}-\left(\mathrm{CN}^{-}\right) \cdot\left(* \mathrm{SO}_{3}^{-2}\right)\right.$.

of the TPPP and some anions are summarized in Table 1. As it is seen, there is a strong interaction between sulfate and TPPP.

Potentiometric responses of the sensors based on TPPP. In next experiments, the TPPP was used as an ionophore in construction of anionselective membrane electrodes for common oryanic and inorganic anions. The potential responses of these sensors in the concentration ranges of $1.0 \times 10^{-5}-1.0$ $\times 10^{-3} \mathrm{M}$ are shown in (Fig. 3). As can be seen from Figure 3. the PVC-based membrane sensor shows very good selectivity towards sulfate ions over other anions.

Besides the critical role of the nature of ion carrier in preparing membrane-selective electrodes, some other important features of the PVC membrane, such as the amount of ionophore, the nature of plasticizer, the plasticizerPVC ratio, and especially, the nature of additives used, are known to significantly influence the sensitivity and selectivity of ion-selective electrodes. ${ }^{18-20}$ Thus, different aspects of membrane preparation based on the TPPP for sulfate ions were optimized and the results are given in lable 2. As can be seen. from Table 2, BA is a more effective solvent mediator Than NPOE, DBP in preparing the sulfate ion-

Table 2. Optimization of membrane ingredients

\begin{tabular}{|c|c|c|c|c|c|}
\hline \multirow{2}{*}{$\begin{array}{l}\text { Number of } \\
\text { membratse }\end{array}$} & \multicolumn{4}{|c|}{ Composition \% } & \multirow{2}{*}{$\begin{array}{c}\text { Slope } \\
\text { (mV per decade) }\end{array}$} \\
\hline & PVC & I'lasticizer & $\left.||^{\prime} P^{\prime}\right|^{3}$ & IIIAI3 & \\
\hline 1 & 32 & $68.13 A$ & 0 & - & $\cdots-2 \mathrm{mV}$ \\
\hline 2 & 32 & $66.13 \mathrm{~A}$ & 2 & - & $-10.7 \pm 0.2$ \\
\hline 3 & 32 & $64.13 \mathrm{~A}$ & 4 & - & $-12.8 \pm 0.1$ \\
\hline 4 & 32 & $62.13 \mathrm{~A}$ & 6 & - & $-14.2 \pm 0.2$ \\
\hline 5 & 32 & $63.13 \mathrm{~A}$ & 5 & - & $-14.7 \pm 0.3$ \\
\hline 6 & 32 & $61.13 A$ & 5 & 2 & $-19.6 \pm 0.3$ \\
\hline 7 & 32 & $60.13 \mathrm{~A}$ & 5 & 3 & $-24.8 \pm 0.5$ \\
\hline 8 & 32 & $59.13 \mathrm{~A}$ & 5 & 4 & $-29.7 \pm 0.2$ \\
\hline$y$ & 32 & 59. NP(OF: & 5 & 4 & $-18.6 \pm 0.3$ \\
\hline 10 & 32 & $59 . \mathrm{I} \mid 3 \mathrm{P}$ & 5 & 4 & $-15.7 \pm 0.1$ \\
\hline 11 & 32 & $64.13 \mathrm{~A}$ & - & 4 & $-4.8 \pm 0.4$ \\
\hline
\end{tabular}


selective electrode. It should be noted that the nature of the plasticizer influences both the dielectric constant of the membrane and the mobility of the ionophore and its complex. The quantity of the ionophore TPPP was also found to affect the sensitivity of the membrane electrode (Nos. 2-5). The sensitivity of the electrode response increases with increasing ionophore content until a value of $5 \%$ is reached. The data given in Table 2 show that the presence of lipophilic additives has a beneficial influence on the performance characteristics of the membrane electrode. Table 2 shows that, addition of $4 \%$ HTAB will increase the slope of the potential response of the sensor from a poor value of $-14.7 \mathrm{mV}$ per decade $(\mathrm{No}, 5)$ to a Nernstian value of $-29.7 \mathrm{mV} / \mathrm{dec} a d e$ (No. 8). The presence of such cationic additives can reduce ohmic resistance $e^{2.3}$ and improve the response behavior and selectivity of the membrane electrodes. ${ }^{2-4}$ Moreover, the additives may catalyze the exchange kinetics at the sample-membrane interface. ${ }^{2 s}$ As is obvious, the best response characteristics are obtained with a membrane composition of $32 \%$ PVC, $59 \%$ BA, $5 \%$ TPPP, and $4 \%$ $\operatorname{HTAB}($ No. 8).

The concentration of the internal solution $\mathrm{K}_{2} \mathrm{SO}_{4}$ in the electrode was changed from $1.0 \times 10^{-3}$ to $1.0 \times 10^{-5} \mathrm{M}$ and the potential response of the sulfate ion-selective electrode was measured. It was found that the variation of the concentration of the internal solution does not cause any significant difference in the potential response, except for an expected change in the intercept of the resulting Nernstian plots. A $1.0 \times 10^{-3} \mathrm{M}$ concentration of the reference solution is quite appropriate for the smooth functioning of electrode system.

The optimum equilibration time for the membrane electrode in the presence of $1.0 \times 10^{-3} \mathrm{M} \mathrm{K}_{2} \mathrm{SO}_{4}$ was $24 \mathrm{~h}$, after which it would generate stable potentials in contact with sulfate solutions. The electrode shows a linear response to the concentration of $\mathrm{K}_{2} \mathrm{SO}_{4}$ ions in the range of $6.3 \times 10^{-6}$ $1.0 \times 10^{-1} \mathrm{M}$ (Fig. 4). The slope of the calibration graph was $-29.7=0.2 \mathrm{mV}$ per decade. The limit of detection, as determined from the intersection of the two extrapolated segments of the calibration graph. was $4.0 \times 10^{-6} \mathrm{M}$.

For analytical application, response time of sensor in

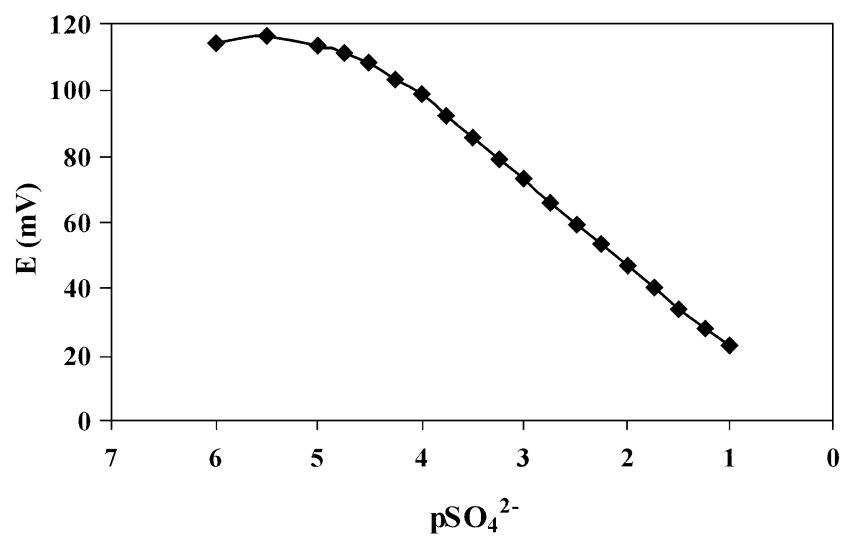

Figure 4. Calibration curves of sulfate electrode hased on TPPP at $\mathrm{pH} 6$.

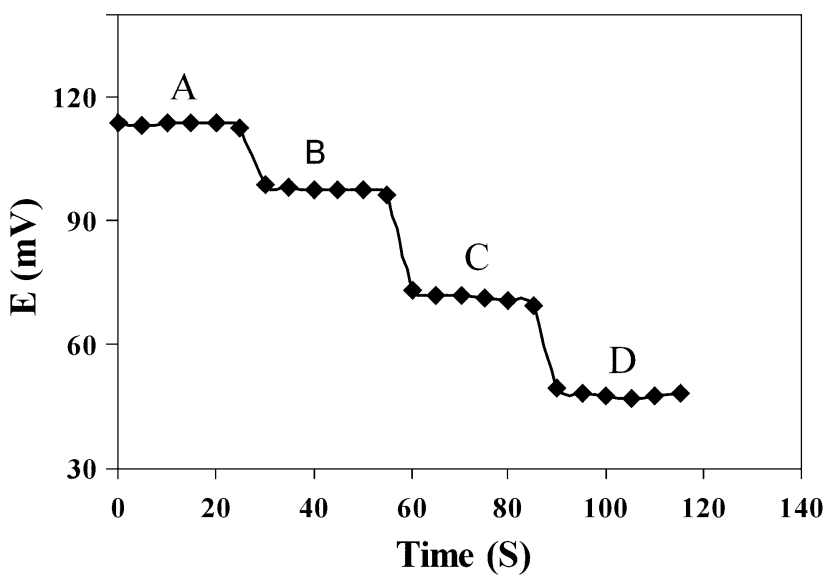

Figure 5. Dynamic response lime of the sultate electrode for step changes in concentration of $\mathrm{SO}^{2}:(\mathrm{N}) 1.0 \times 10^{5} \mathrm{M}$. (B) $\mathrm{I} .0 \times 10^{+}$ M. (C) $1.0 \times 10^{-3}$ M. (D) $1.0 \times 10^{-2} \mathrm{M}$.

different concentrations is an important factor. In this study, the practical response time was recorded by immediate changing of sulfate concentration from $1.0 \times 10^{-5}$ to $1.0 \times$ $10^{-1} \mathrm{M}$ and the results are shown in Figure 5. As it is seen, in whole concentration ranges, the sensor reaches to the equilibrium response in a very short time $(6 \mathrm{~s})$.

The influence of the $\mathrm{pH}$ of the test solution $\left(1.0 \times 10^{-3} \mathrm{M}\right.$ of $\left.\mathrm{K}_{2} \mathrm{SO}_{4}\right)$ on the potential responses of the sulfate PVCbased membrane electrode was tested in the $\mathrm{pH}$ range 2.0 12.0. and the results are depicted in Figure 6. As it is seen. the response of the sensor is independent of the $\mathrm{pH}$ in the range 2.5-9.5. At higher alkaline media, the potential changed sharply, due to the response of the sensor to both sulfate and hydroxide ions. At lower $\mathrm{pH}$ than 2.5, due to the protonation of sulfate ions (formation of $\mathrm{HSO}_{4}^{-}$). the potential response of the sensor increases.

Potentiometric selectivity coefficients, describing the preference of the TPPP-based membrane sensor for an interfering ion, $\mathrm{B}$, relative to sulfate ion, $\mathrm{A}$, were determined by the matched potential method. ${ }^{20}$ According to this method, the specified activity (concentration) of the primary ion $\left(\mathrm{A}=1.0 \times 10^{-5}-1.0 \times 10^{-4} \mathrm{M}\right)$ is added to a reference solution $\left(5.0 \times 10^{-6} \mathrm{M}\right)$, and the potential is measured. In a

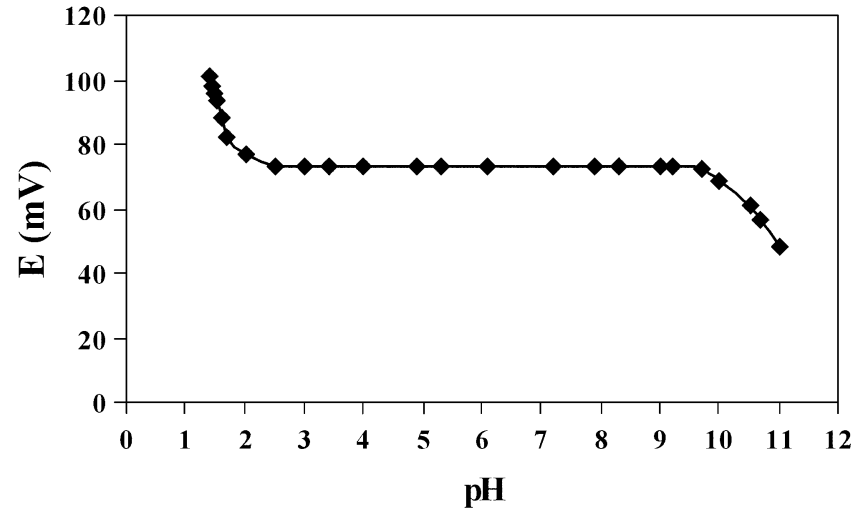

Figure 6. The effect of the $\mathrm{pH}$ of the test solution on the potential response of the sulfate semsor. 
Table 3. Selectivity coeflicients of various interlering anions

\begin{tabular}{|c|c|}
\hline Amions & $K_{A H}^{m}$ \\
\hline $\mathrm{SCN}$ & $3.10 \times 10^{3}$ \\
\hline $\mathrm{Cl}$ & $1.78 \times 10^{3}$ \\
\hline $\mathrm{H}_{2} \mathrm{PO}_{4}$ & $1,12 \times 10^{3}$ \\
\hline $\mathrm{ClI}_{3} \mathrm{COO}$ & $5.62 \times 10^{4}$ \\
\hline $\mathrm{CN}$ & $3.16 \times 10^{4}$ \\
\hline $\mathrm{SO}_{3}^{2}$ & $2.24 \times 10^{4}$ \\
\hline $\mathrm{NO}_{3}$ & $5.41 \times 10^{4}$ \\
\hline $\mathrm{NO}_{2}$ & $1.99 \times 10^{3}$ \\
\hline 1 & $4.47 \times 10^{4}$ \\
\hline $\mathrm{ClO}_{4}^{-}$ & $6.52 \times 10^{-4}$ \\
\hline
\end{tabular}

separation experiment, the interfering ion $\left(B=1.0 \times 10^{-1}\right.$ $\left.1.0 \times 10^{-3} \mathrm{M}\right)$ is successively added to an identical reference solution until the measured potential matched that obtained before by adding the primary ions. The matched potential method selectivity coefficients, is then given by the resulting primary ion to interfering ion activity (concentration) ratio. The selectivity coefficients for various anions are summarized in Table 3. As it is seen, for all organic and inorganic anions used, the selectivity coefficients are smaller than $3.1 \times 10^{-3.3}$. indicating that, they would not significantly disturb the functioning of the sulfate ion-selective electrode.

Table 4 compared the selectivity coefficients of the proposed membrane sensor with those reported before. ${ }^{11-15}$ Noteworthy, this is just a gross relative comparison, since the selectivity data have been reported using different experimental methods as indicated in Table 4. As it is seen, the proposed sensor in term of selectivity coefficients is superior to those previously reported by the other researchers. ${ }^{1-15}$

The proposed membrane sensor was found to work well under laboratory conditions. The sensor was used as an indicator electrode in the titration of sulfate ion $\left(1.0 \times 10^{-1}\right.$

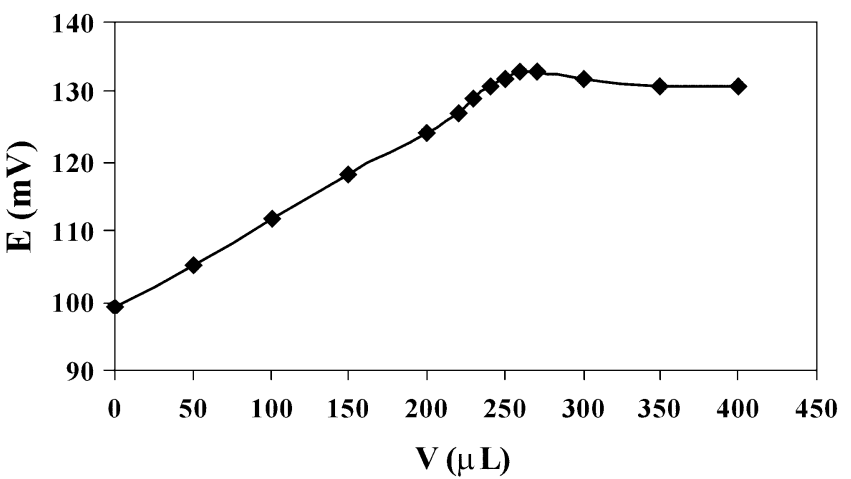

Figure 7. Potentiometric titration curve of $25.0 \mathrm{ml} 1.0 \times 10^{4} \mathrm{M}$ solution of $\mathrm{SO}_{4}^{3-}$ with $1.0 \times 10^{-2} \mathrm{Mol}^{3} \mathrm{Ba}^{2-}$.

M) with a standard barium solution $\left(1.0 \times 10^{-2} \mathrm{M}\right)$. The results of titration are shown in Figure 7 , indicating that the amount of sulfate ion can be accurately determined with the electrode.

The sensor was also used for direct determination of salbutamol sulfate and paromomycine sulfate. $0.1 \mathrm{~g}$ of powdered of each compound was dissolved in $100 \mathrm{ml}$. of distilled water and the sulfate content of the resulting solutions were then determined by the proposed sensor using the calibration method. The results obtained by the sensor together with those obtained by gravimetric method and declared amounts are summarized in Table 5. As it is seen, there are satisfactory agreements between the results obtained by the proposed sulfate sensor and those by gravimetric method and declared amounts.

\section{References}

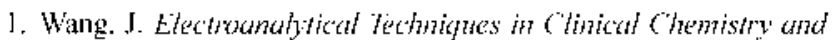
Labotatory Wedicine: VCI: New York. 1988.

Table 4. Comparison of selectivity coellicients $\left(K_{A, \beta}\right)$ for dillerent sulfiate ion- selective electrodes

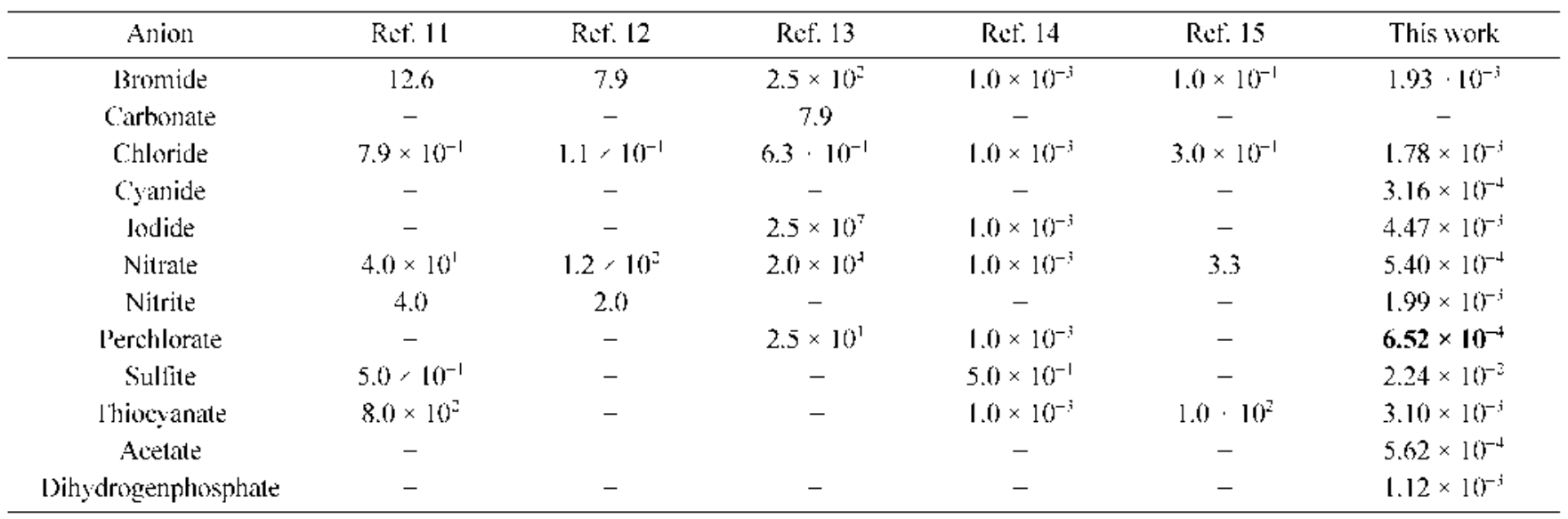

Table 5. I Jetermination of Sabbutamol sullate and Paromomycin sullate by ube proposed semsor

\begin{tabular}{cccc}
\hline Drugs & lSE method & Gravimetric method & [eclared amount \\
\hline Salbutanol sulfate & $65.4 \perp 0.1(\% \mathrm{WW})$ & $66.2 \perp 0.3(\% \mathrm{~W} / \mathrm{W})$ & $67 \perp 0.2(\% \mathrm{~W} / \mathrm{W})$ \\
l'aromomycin sulfate & $63.2 \perp 0.4(\% \mathrm{WW})$ & $63.7 \perp 0.3(\% \mathrm{~W} / \mathrm{W})$ & $64 \pm 0.3(\% \mathrm{~W} / \mathrm{W})$ \\
\hline
\end{tabular}


2. Electrochemical Detection Techinques in the Applied Biosciences: Junter. G. A.. Ed.: Ellis Horwood: Chichester. UK. 1998.

3. Schulthess. P.: Ammanu. D.: Krautler. B.: Caderas, C.: Stepanek: R.: Sinnon. W. Antal Chent 1985, 57. 1397.

4. Stepanek. R: Kraulter. B.: Schulthess. P.: Lindemann. B.: Ammann. D.: Simon. W. Afol. Chim. Acta 1986. 182.83.

5. Amini. M. K.: Shahrokhian. S.: Tangestaninejad. S. Anal. Chem. 1999. 71.2502

6. Meverhoff, M. E.: Pranitis. D. M.: Ym. H. S. Chaniotakis. N. A.: Park. S. B. Anat Chim Acta 1989. 217. 123.

7. Yuan. R: Chai, Y.: Lilı. D.: Gao, D: Li, J: Yu, R. Anal Chent. 1993. 65.2572

8. Wuthier. U.: Pham. H. V: Zand. R: Welti. D.: Funck. R. J. J: Bezegh. A.: Ammann. D.: Pretsch. E.: Simon. W. Anal. Chem. $1984,56,535$

9. Amini, M. K.: Shahrokhian. S.: Tangestaninejad. S. Anal. Chim. tcta 1999. 402,137

10. Badr. I. H. A.: Meyerhotf. M. E.: Hassan. S. S. M. Anal. Chem. 1995.67.754

11. Nishizawa. S.: Bühlmann. P.: Xiao. K. P.: Umezawa. Y. Anal. Chim. Acta 1998, 35, 358.

12. Li, Z. Q: Lilı. G. D.: Duan, L. M.: Shen, G. L: Yu. R. Q. Anal. Chim. Acta 1999,165,382.

13. Fibbioli. M.: Berger. M.: Schmidtchen. F.: Pretsch. E. Anal. Chem. 2000. 72.156

14. Berrocal. M. J.: Cruz. A.: Badr. I. H. A.: Bachas. L. G. Afral.
Chem. 2000. 72. 5295.

15. Morigi. M.: Scavetta. E.: Berrettoni. M.: Giorgetti. M.: Tonelli. D. Anal Chim Acta 2001, $\$ 39,265$

16. Wizinger. R Heh: Chent Acta 1956, 5,39 .

17. Shamsipur. M: Yousefi. M.: Hosseini. M: Ganjali, M. R. Anot Chem. 2002. 7f. 5538.

18. Gariali. M. R.: Poursaberi. T.: Basiripour. F.: Salavati-Niasari. M.: Youseti. M.: Shamsipur. M. Fizsmius. J. Anal. Chem 2001. 370 . 1091 .

19. Ganjali, M. R.: Pourjavid, M. R:; Rezapour. M.: Haghgoo, S. Sens. Actnatons $B$ 2003, 89,21

20. Ganjali. M. R.: Poursaberi. T.: Hosseini. M.: Salaøati-Niasari. M.: Yousefi. M.: Shamsipur. M. Anal. Sci. 2002. 18. 289

21. Ganjali. M. R.: Naji. L.: Poursaberi. T.: Taghizadeh. M.: Pirelahi. H. Yousefi, M.: Yeganeh-Faal, A.; Shamsipur. M. Talanta 2002. 58.359 .

22. Lerchi. M.: Orsini, F.: Cimerman. Z.: Pretsch, E.; Chowdhury, D. A.: Kamata. S. Anal Chem. 1996. 68.3210

23. Ammann. D.: Pretsch. E.: Simon. W.: Lindner. E.: Bezegh. A.: Pungor. E. Anal. Chim Acta 1985. 171. 119

24. Ammann. D.; Pretsch. E.; Simon, W.; Lindner. E.; Jeny: J:; Toth K ; Pungor. E. Anal Chent 1991, 63, 1380.

25. Gehring. P. M: Morf. W. E.: Welti, M; Pretsch, E.: Simon. W Helv Chim. Acta 1990. 73. 203.

26. Unnezawa. Y: Unezawa. K.: Sato. H. Pwe Appl. Chem. 1995.67. 507. 